\title{
Expression of Clara Cell Secretory Protein in the Lungs of Rats Exposed to Crystalline Silica In Vivo
}

\author{
Yasuo Morimoto, Hiroko Nagatomo, Masami Hirohashi, Takako Oyabu, Akira Ogami, \\ Hiroshi Yamato, Kaori Kuroda, Yasuko Obata, Toshiaki Higashi and Isamu Tanaka \\ Institute of Industrial and Ecological Sciences, University of Occupational and Environmental Health, Japan
}

\begin{abstract}
Expression of Clara Cell Secretory Protein in the Lungs of Rats Exposed to Crystalline Silica In Vivo: Yasuo Mовıмото, et al. Department of Occupational Pneumology, Institute of Industrial and Ecological Sciences, University of Occupational and Environmental Health-It has been theorized that Clara cell secretion protein (CCSP) plays a critical role in regulating the acute inflammatory response in the lung. We hypothesized that CCSP is also related to lung injury induced by occupational dust. The present study was conducted to investigate the time course of the expression of CCSP in lungs exposed to crystalline silica in vivo. Male Wistar rats were administered $1 \mathrm{mg}$ or $2 \mathrm{mg}$ of silica suspended in saline by a single intratracheal instillation and were sacrificed at $3 \mathrm{~d}, 1 \mathrm{wk}, 1$ month, 3 months and 6 months of recovery time. The expression of CCSP was observed by RT-PCR and western blot analysis. Exposure to $2 \mathrm{mg}$ of silica decreased in levels of CCSP mRNA at $3 \mathrm{~d}, 1 \mathrm{wk}, 1$ month and 6 months following intratracheal instillation. The protein level of CCSP in silica-exposed rats was decreased at $3 \mathrm{~d}, 7 \mathrm{~d}$ and 1 month after a single instillation of $2 \mathrm{mg}$. The decreases in CCSP at the acute phase in this experiment suggest that CCSP may regulate the acute injury of the lung exposed to silica.
\end{abstract}

(J Occup Health 2005; 47: 504-509)

Key words: CCSP, Crystalline silica, Clara cell

Environmental agents such as silica and asbestos are known to have fibrogenic potential, however the mechanisms of the fibrogenicity of dust have not been satisfactorily elucidated $^{1,2)}$. It is thought that not only a

Received May 19, 2005; Accepted Sep 7, 2005

Correspondence to: Y. Morimoto, Department of Occupational Pneumology, Institute of Industrial and Ecological Sciences, University of Occupational and Environmental Health, 1-1 Iseigaoka, Yahatanishi, Kitakyushu 807-8555, Japan (e-mail: yasuom@med.uoeh-u.ac.jp) fibrosis-stimulating agent but also inhibiting factors may be related to the process of fibrosis in the lung ${ }^{3)}$. An imbalance between these fibrosis-stimulating and inhibiting factors causes bronchiolar and alveolar epithelial cell damage, leading to pulmonary fibrosis. Some of the anti-inflammatory molecules, expressed by the bronchiolar and alveolar epithelium, have been reported to inhibit infiltration of inflammatory cells and deposition of collagen in the lung. Among them, Clara cell secretory protein $(\mathrm{CCSP})^{4)}$ is one of the major secretory products specifically produced by Clara cells and is thought to inhibit inflammation and fibrosis since it is homologous with lipocortin. It has been theorized that CCSP also plays a role as a phospholipase $\mathrm{A}_{2}$ inhibitor in suppressing inflammation and fibrosis ${ }^{5)}$. There are some reports ${ }^{5-6)}$ that CCSP is suspected to inhibit hyperoxia-induced lung injury, early onset of lung edema, and production of proinflammatory cytokines such as IL1 beta, IL-3 and IL- 6 using CCSP knockout mice, and that CCSP inhibits chemotaxis of fibroblasts in vitro. Decreased levels of CCSP have been reported in bronchoalveolar lavage fluid (BALF) from patients with idiopathic pulmonary fibrosis ${ }^{7)}$. A reduction in the levels of fibrosis-suppressing factors may contribute to pulmonary fibrosis.

In order to determine whether or not CCSP is associated with lung injury induced by dusts, we made serial measurements of expression of CCSP in the rat lung following the intratracheal instillation of crystalline silica.

\section{Materials and Methods}

Animals

The male Wistar rats used in this study were purchased from Kyudo (Japan) at $10 \mathrm{wk}$ old. Either saline or a crystalline silica suspension ( $1 \mathrm{mg}$ or $2 \mathrm{mg} / 0.4 \mathrm{ml}$ saline) was administered to the animal intratracheally. The animals were maintained for $3 \mathrm{~d}, 1 \mathrm{wk}, 1$ month, 3 months, and 6 months of recovery. The animals were assigned to an exposed group $(n=5)$ and a control group $(n=5)$ for 
each exposure category. After completion of the exposure time, the animals were sacrificed with an overdose of phenobarbital by intraperitoneal injection. The rats were handled according to the guidelines described in the Japanese Guide for the Care and Use of Laboratory Animals as approved by the Animal Care and Use Committee, University of Occupational and Environmental Health, Japan.

\section{Dust sample}

The particle material used in the study was crystalline silica (Min-U SIL 5, U.S. Silica Co., Berkeley Springs, USA). The geometric mean diameter and standard deviation was $1.6 \mu \mathrm{m}$ and $2.0 \mu \mathrm{m}$, respectively. The mass median aerodynamic diameter was $3 \mu \mathrm{m}$ as measured by a cascade impactor.

Preparation of RNA, cDNA Synthesis, and polymerase chain reaction

Total RNA from the lung was prepared in the presence of guanidium thiocyanate ${ }^{8}$. Single-strand cDNA was synthesized with Moloney murine leukemia virus-derived reverse transcriptase (Perkin Elmer, USA) using $500 \mu \mathrm{g}$ of total RNA. An equal amount of cDNA from each sample was amplified by specific primers for each gene ${ }^{9)}$. Amplification was performed with a thermocycler (Astech, Japan) under the following conditions: denaturation at $94^{\circ} \mathrm{C}$ for 45 seconds, annealing at $60^{\circ} \mathrm{C}$ for $45 \mathrm{~s}$, and extension at $72^{\circ} \mathrm{C}$ for $2 \mathrm{~min}$ for the target gene. The primers specific for the amplification of rat CCSP gene (5'primer, $5^{\circ}$ CGGACATCTGCCCAGGATTTCT-3 '; 3 'primer, 5 ‘ACACAGAGGACTTGTTAGGAT-3', size of the amplified fragment, $208 \mathrm{bp}$ ) were used. The number of thermocycles was 19 , allowing quantitation without saturation in our experiments ${ }^{10)}$. Human $\beta$-actin gene (5'primer, 5'-ATCATGTTTGAGACCTTCAACACC-3'; 3 'primer, 5'-TAGCTCTTCTCCAGGGAGG-3'; size of the amplified fragment, $357 \mathrm{bp}$ ) was used as an internal standard. The fragments amplified by polymerase chain reaction (PCR) were detected by electrophoresis on $2 \%$ agarose gel. The PCR products were resolved using gel electrophoresis and visualized by ethidium bromide staining. The gel was photographed with Polaroid Type 665 positive/negative film (Polaroid Corporation, USA) under ultraviolet light at identical exposures and development times. The bands from the positive film were scanned, and the densities of the CCSP and $\beta$-actin PCR products were measured using National Institute of Health (NIH) Image 1.55 software.

\section{Western blot analysis}

Lung tissue stored at $-70^{\circ} \mathrm{C}$ was homogenized in 10 $\mathrm{mM}$ Tris- $\mathrm{HCl}$ ( $\mathrm{pH} 7.5$ ) containing proteinase inhibitor cocktail tablets (Roche Diagnostics GmbH, Germany). The lung homogenate samples were centrifuged at 27,000 $\mathrm{g}$ for $10 \mathrm{~min}$. The supernatants were used for protein assay (Bio-Rad, USA).

Thirty micrograms of lung homogenate protein were added to gel loading buffer (final conc. $50 \mathrm{mM}$ Tris, 70 $\mathrm{mM} \mathrm{NaCl}, 1 \%$ SDS, 5\% 2-mercaptoethanol), and were electrophoresed on polyacrylamide gel $(15 \%)$ in the presence of $0.1 \%$ SDS using the Mini protean 3 Electrophoresis system (Bio-Rad Laboratories, USA). The samples were electrophoretically blotted on polyvinylidene difloride membrane (ECL western blotting detection system, Amersham Biosciences Inc., USA) at $25 \mathrm{~V}$ for $1 \mathrm{~h}$ using transblot apparatus. They were then incubated with $3 \%$ milk-Tris-buffered saline-Tween 20 for one hour, and incubated at room temperature overnight with rabbit anti-human urine protein 1 (human CCSP, dilution 1/1,000) (Dako, Denmark) and/or and goat antihuman actin (Santa Cruz Biotechnology Inc., USA) as an internal control in 3\% milk-Tris-buffered saline-Tween 20. After three washings, the membrane was incubated with peroxidase-conjugated sheep anti-rabbit IgG (Amersham Biosciences Inc., USA) (dilution 1/5,000) for one hour. It was then washed three times, and the signals were finally visualized using the enhanced chemiluminescence system (Amersham Biosciences, USA). The bands of CCSP and actin were analyzed with NIH Image 1.56 software.

\section{Tissue preparation for immunohistochemistry}

After removal of the right lung, the left lung was inflated and fixed by intratracheal instillation of $4 \%$ paraformaldehyde at $25 \mathrm{~cm} \mathrm{H}_{2} \mathrm{O}$ pressure. The lung and trachea were resected from the surrounding tissue, and allowed to stand at $4^{\circ} \mathrm{C}$ for $24 \mathrm{~h}$. The tissue was washed for $10 \mathrm{~min}$ in phosphate-buffered saline, dehydrated by immersion in a graded series of ethanol washes for $1 \mathrm{~h}$ per wash, then maintained in $100 \%$ ethanol at $4{ }^{\circ} \mathrm{C}$. The lung tissue was embedded in paraffin, and sections were cut out from the lobe. Immunostaining for CCSP was performed using $8 \mu \mathrm{m}$ sections. Rabbit anti-human urine protein 1 (human CCSP) antibody from Dako (Denmark) was used as the primary antibody and was detected by the avidin-biotin-peroxidase staining method using the DAKO LSAB Kit (Dako Corporation, USA). Tissue sections were counterstained with hematoxylin.

\section{Statistical analysis}

We used the non-parametric statistical test, MannWhitney test, for silica-exposed and control groups. Values are expressed as the mean \pm one standard deviation of 5 animals. Differences at $\mathrm{p}<0.05$ were considered statistically significant by the test.

\section{Results}

Expression of CCSP mRNA (Fig.1)

Levels of CCSP mRNA in the lung were significantly 

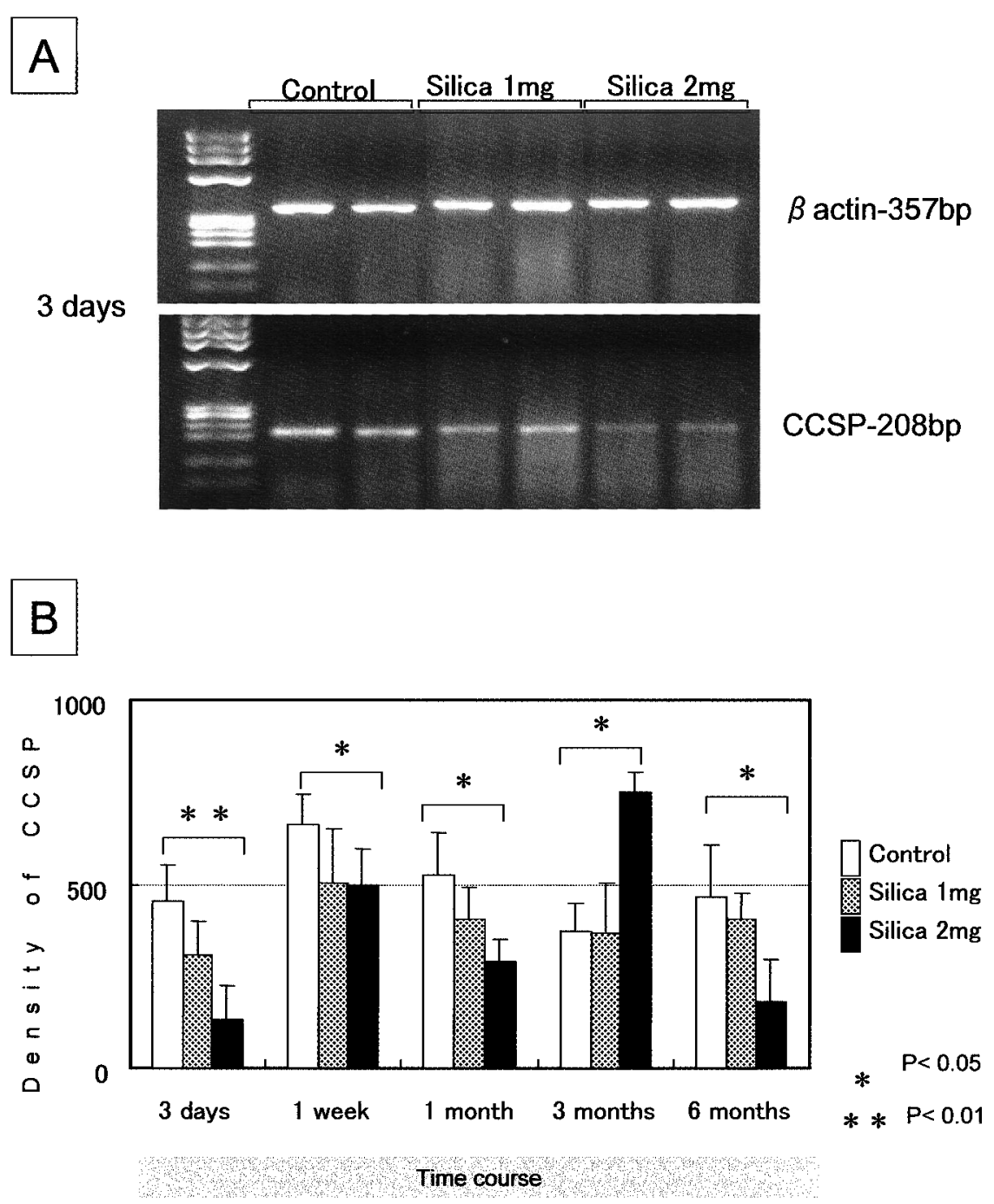

Fig. 1. Gene expression of CCSP mRNA in the lungs of rats: (A) RT-PCR analysis of total RNA extracted from rat lungs exposed to crystalline silica at $3 \mathrm{~d}$ recovery; (B) Time course of expression of CCSP mRNA in rat lungs exposed to crystalline silica. Each column and bar represents the mean \pm standard deviation.

lower at $3 \mathrm{~d}, 1 \mathrm{wk}$ and 6 months after intratracheal instillation in the $2 \mathrm{mg}$ silica exposed groups than in the control group. On the other hand, the CCSP mRNA level was significantly higher after 3 months recovery in the silica-exposed groups than in the control groups. The ratio of CCSP to $\beta$-actin also had a similar pattern to the levels of CCSP.

\section{Expression of CCSP protein (Fig. 2)}

Protein expression of CCSP was significantly decreased at 1 month and 3 months recovery from exposure to $1 \mathrm{mg}$ silica, and also at $3 \mathrm{~d}, 1 \mathrm{wk}$ and 1 month of recovery from exposure to $2 \mathrm{mg}$ silica. At 6 months of recovery, $2 \mathrm{mg}$ of silica exposure significantly elevated the protein expression of CCSP. The ratio of
CCSP to actin also had a similar pattern to the protein expression of CCSP.

Immunohistochemical staining for CCSP (Fig. 3)

Anti-CCSP immunostaining in the control group showed staining of the epithelial cells of the proximal and peripheral airways. In groups exposed to $2 \mathrm{mg}$ silica, CCSP staining of the epithelial cells was less marked at $3 \mathrm{~d}$ of recovery. Anti-CCSP immunostaining at 6 months of recovery revealed positive staining of regenerated epithelial cells.

\section{Discussion}

CCSP is thought to act as a phospholipase $\mathrm{A}_{2}$ inhibitor and to suppress inflammation as it inhibits the production 


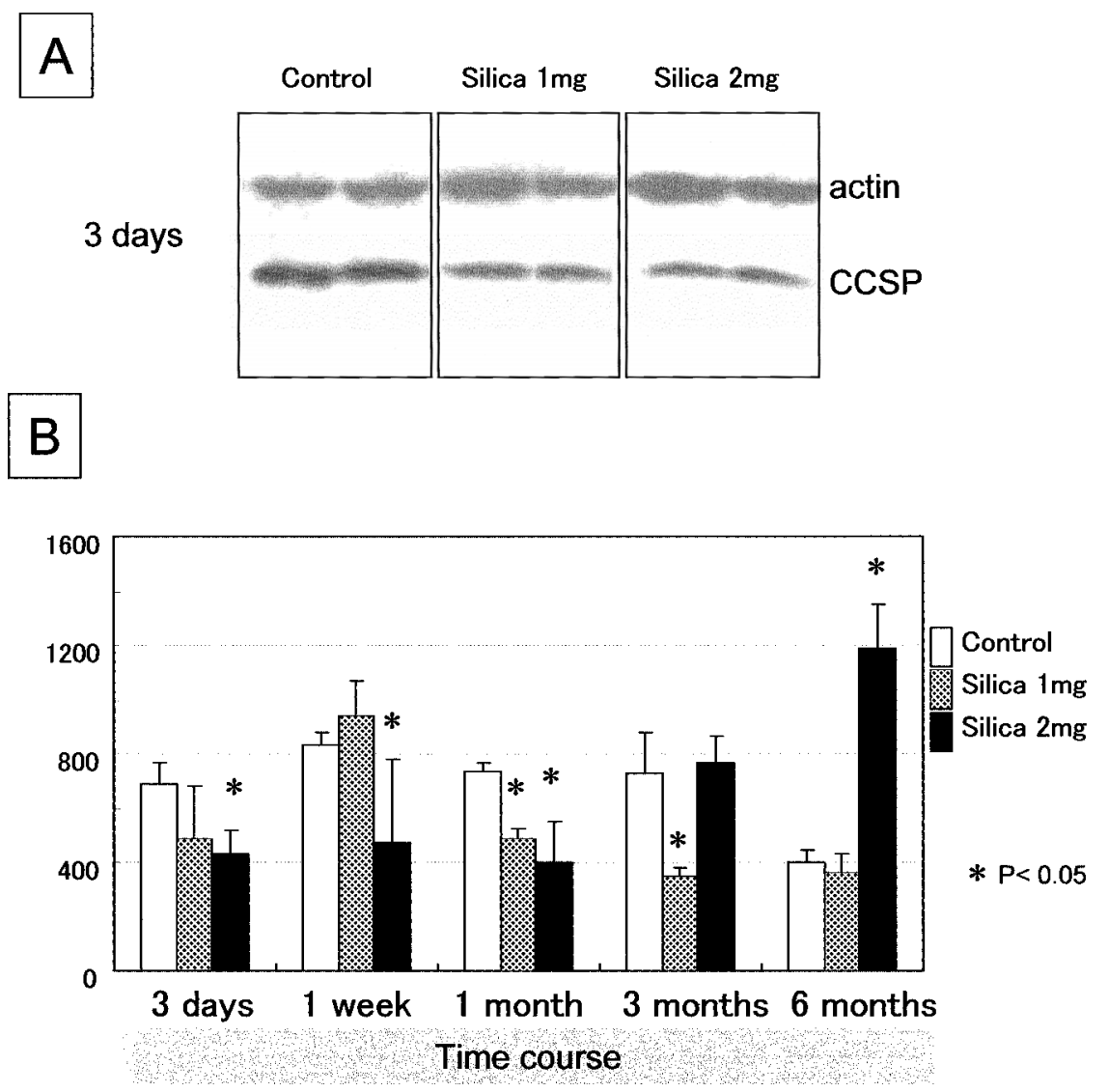

Fig. 2. Protein expression of CCSP in the lungs of rats: (A) Western blot analysis showing CCSP production in rat lungs exposed to crystalline silica at $3 \mathrm{~d}$ recovery; (B) Time course of protein expression of CCSP in rat lungs exposed to crystalline silica. Each column and bar represents the mean \pm standard deviation.
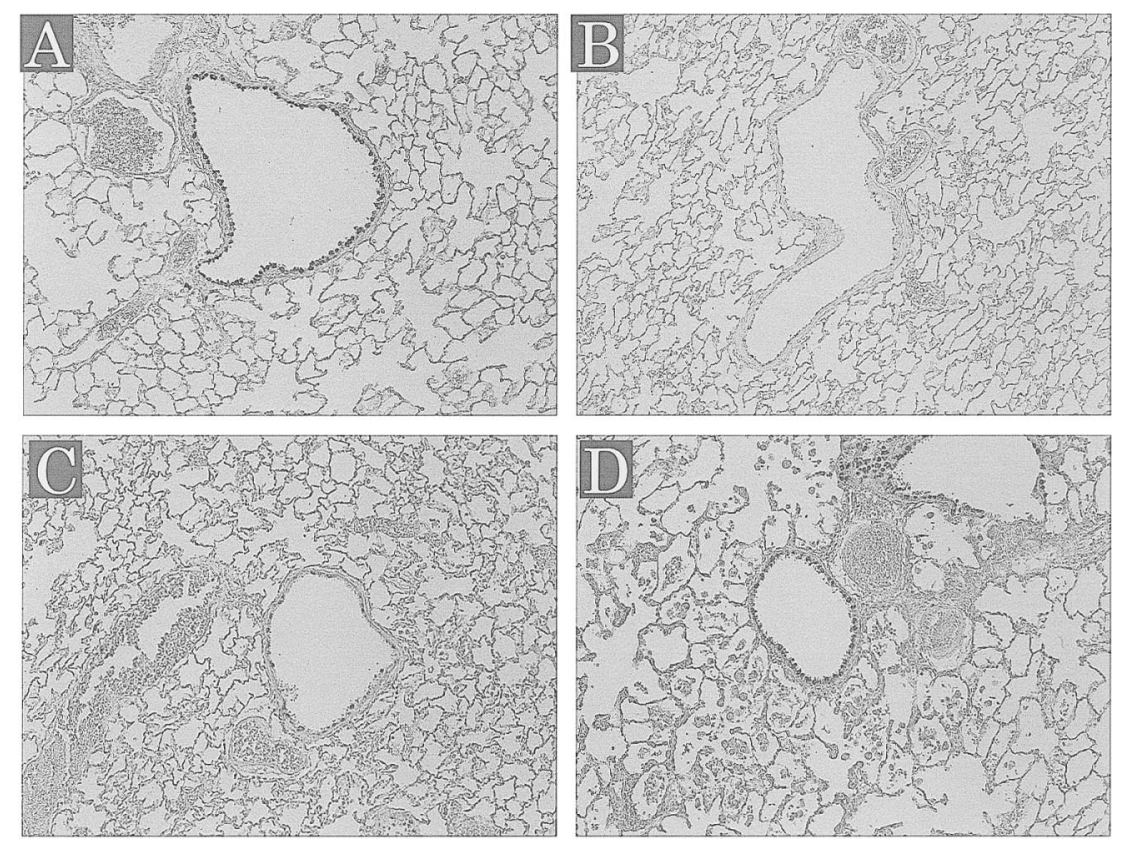

Fig. 3. Lung sections from silica-exposed rat immunostained for CCSP: (A) saline-exposed (control) lung after $3 \mathrm{~d}$ of recovery; (B) Silica-exposed lung after $3 \mathrm{~d}$ of recovery; (C) Silica-exposed lung after 1 month of recovery; (D) Silica-exposed lung after 6 months of recovery. Magnification $\times 100$. 
and release of proinflammatory cytokines ${ }^{4}$. In this experiment, exposure to silica decreased the expression of CCSP in lung tissue at both the protein and the mRNA level in the acute phase. For acute lung injury, Arsalane $\mathrm{K}$ et al. ${ }^{11)}$ reported that CCSP concentrations in BALF, as well as the levels of CCSP mRNA and CCSP protein in lung tissue, were decreased in a lipopolysaccharide (LPS) exposed rat model they had prepared for study. Daly HE et al $^{12)}$ also observed a decrease in CCSP mRNA expression in lung tissue in a rat bleomycin model of pulmonary fibrosis. In our previous study on CCSP expression in a dust-exposed rat model, we reported a decrease in CCSP in the acute phase in crocidolite exposed rats in which fibrosis was prolonged ${ }^{2)}$, whereas no marked decrease was found in silicon carbide-exposed rats in which reversible fibrosis was present ${ }^{13)}$. Since exposure to silica resulted in progression of fibrotic processes during the experimental period in our previous study ${ }^{2)}$, it appears to be consistent with results obtained from other dusts or agents which are fibrogenic. The possible mechanisms for the decrease of CCSP expression at the transcriptional level were suggested as follows:

Injury to the epithelial cells of the terminal airway due to silica exposure is suggested. Pathological findings showed some, thought not significant, hyperplasia of epithelial cells in the terminal airway which occurred as damage to the epithelium in the acute phase. We think that the epithelial cells may not be mature enough to secrete CCSP protein just after lung injury. Barth et al. ${ }^{14)}$ reported that there was a negative relationship between production of CCSP and proliferative activity. In our previous study, slow but progressive fibrosis was also observed in the chronic phase ${ }^{2)}$. Only damage of airway and alveolar epithelial cells led to progression of fibrosis in the lung tissue of animal models ${ }^{13)}$, suggesting that severe injury of epithelial cells might have taken place physiologically in the present experiment.

CCSP, in its promoter region, has some domains which regulate gene expression; and the domains may be involved in lung injury. Complicated expression regulatory actions via CCAAT/enhancer binding protein (C/EBP)beta or Nkx2.1. have been reported ${ }^{16)}$. These actions have been reported in animal models in which lung injury was produced by exposure to high oxygen concentrations. Silica exposure probably induces lung injury, therefore, in this regard there could be a variety of mechanisms by which it acts to regulate gene expression. Expression of CCSP protein in the lung tissue in the chronic phase six months after exposure was increased, whereas that of CCSP at the transcriptional level was decreased. In our previous intratracheal instillation study, we found decreased mRNA levels, although we did not examine protein levels following intratracheal instillations of crocidolite ${ }^{17)}$. Furthermore, exposure to silicon carbide produced no decrease in protein levels, however, decreases in mRNA levels were observed $^{13)}$. The levels of expression of protein and mRNA were more or less different. For reasons that remain obscure, however, mechanisms causing this discrepancy may lie in the regulation of CCSP degradation. Ramos et al. ${ }^{18)}$ reported that silica-induced granulomas in the late phase showed lower proteinase expression than in the early phase in animals. Increased levels of mRNA expression were observed 3 months after silica exposure, indicating that a state of continuing increases in the production of CCSP in Clara cells may have been present.

As for potassium octatitanate whiskers ${ }^{9)}$ and silicon carbide $^{13)}$, a temporary restoration of CCSP mRNA expression was observed at 3 months after exposure; and, although not an increase on original levels, a similar restoration trend was observed for other dusts. Possibly, due to silica's greater fibrogenicity, CCSP maintained an excessive increase in production in order to protect the lung from fibrosis, after mature epithelial cells increased in the repair process.

In summary, we made serial measurements of the gene expressions of CCSP mRNA and protein in the rat lung following intratracheal instillation of crystalline silica to determine the role of CCSP in pulmonary fibrosis induced by silica. Not only mRNA levels but protein levels of CCSP decreased at the acute phase after a single dose of instillation. These data suggest that CCSP may regulate lung injury exposed to silica.

\section{References}

1) MR Becklake: Asbestos-related diseases of the lung and other organs: their epidemiology and implications for clinical practice. Am Rev Respir Dis 114, 187-227 (1976)

2) A Ogami, Y Morimoto, $H$ Yamato, $T$ Oyabu, $T$ Kajiwara and I Tanaka: Patterns of histopathological change determined by the point counting method and its application for the hazard assessment of respirable dust. Inhalation Toxicology 16, 793-798 (2004)

3) RK Coker and GJ Laurent: Pulmonary fibrosis: cytokines in the balance. Eur Respir J 11, 1218-1221 (1998)

4) G Mantile, L Miele, ME Cordella, G Singh, SL Katyal and AB Mukherjee: Human Clara cell 10-kDa protein is the counterpart of rabbit. J Biol Chem 268, 2034320351 (1993)

5) O Lesur, A Bernard, K Arsalane, R Lauwerys, R Begin, A Cantin and D Lane: Clara cell protein (CC-16) induces a phospholipase A2-mediated inhibition of fibroblast migration in vitro. Am J Respir Crit Care Med 152, 290-297 (1995)

6) GW Mango, CJ Johnston, SD Reynolds, JN Finkelstein, CG Plopper and BR Stripp: Clara cell secretory protein deficiency increases oxidant stress response in conducting airways, Am J Physiol 275, L348-L356 (1998) 
7) O Lesur, AM Bernard and RO Begin: Clara cell protein (CC-16) and surfactant-associated protein A (SP-A) in asbestos-exposed workers. Chest 109, 467-474 (1996)

8) P Chomczynski and N Sacchi: Single-step method of RNA isolation by acid guanidinium thiocyanatephenol-chloroform extraction. Anal Biochem 162, 156159 (1987)

9) L Ding, Y Morimoto, T Oyabu, H Kim, A Ogami, K Yatera, M Hirohashi, H Yamato, H Hori, T Higashi and I Tanaka: Gene expression of clara cell secretory protein, surfactant protein-A and thyroid transcription factor- 1 in the lungs of rats exposed to potassium octatitanate whiskers in vivo, J Occup Health 43, 111117 (2001)

10) Y Morimoto, T Tsuda, H Hori, H Yamato, A Ohgami, T Higashi, N Nagata, M Kido and I Tanaka: Combined effect of cigarette smoke and mineral fibers on the gene expression of cytokine mRNA. Environ Health Perspect 107, 495-500 (1999)

11) K Arsalane, F Broeckaert, B Knoops, M Wiedig, G Toubeau and A Bernard: Clara cell specific protein (CC16) expression after acute lung inflammation induced by intratracheal lipopolysaccharide administration. Am J Respir Crit Care Med 161, 16241630 (2000)

12) HE Daly, CM Baecher-Allan, RK Barth, CT D'Angio and JN Finkelstein: Bleomycin induces straindependent alterations in the pattern of epithelial cellspecific marker expression in mouse lung. Toxicol Appl
Pharmacol 142, 303-310 (1997)

13) Y Morimoto, L Ding, T Oyabu, M Hirohashi, H Kim, A Ogami, H Yamato, I Akiyama, H Hori, T Higashi and I Tanaka: Expression of Clara cell secretory protein in the lungs of rats exposed to silicon carbide whisker in vivo, Toxicol Lett 145, 273-279 (2003)

14) PJ Barth, S Koch, B Muller, F Unterstab, P von Wichert and R Moll: Proliferation and number of Clara cell 10$\mathrm{kDa}$ protein (CC10)-reactive epithelial cells and basal cells in normal, hyperplastic and metaplastic bronchial mucosa, Virchows Archiv: an international journal of pathology. 437, 648 (2000)

15) N Hagimoto, K Kuwano, H Miyazaki, R Kunitake, M Fujita and M Kawasaki: Induction of apoptosis and pulmonary fibrosis in mice in response to ligation of Fas. Am J Respir Cell Mol Biol 17, 272-278 (1997)

16) PL Ramsay, Z Luo, A Major, MS Park, M Finegold, SE Welty, I Kwak, G Darlington and FJ Demayo: Multiple mechanisms for oxygen-induced regulation of the Clara cell secretory protein gene. Faseb J 17, 2142-2144 (2003)

17) Morimoto Y: Epithelial cells-Modifiers of lung injury. Journal of UOEH 25, 259-267 (2003)

18) RJ Perez, SVM de Lourdes, B Vanda, M Selman M and A Pardo: Matrix metalloproteinases 2, 9, and 13, and tissue inhibitors of metalloproteinases 1 and 2 in experimental lung silicosis. Am J Respir Crit Care Med 160, 1274-1282 (1999) 